\title{
COMPARISON OF ASSIMILATE PARTITIONING IN ORGANICALLY AND CONVENTIONALLY GROWN TEA
}

\author{
WGC Wekumbura ${ }^{1}$, AJ Mohotti ${ }^{2}$, LP Vidhana Arachchi ${ }^{1}$ and KM Mohotti ${ }^{2}$
}

\begin{abstract}
The partitioning of assimilates were compared in organically and conventionally grown tea. Dry matter and nutrient partitioning was examined in 12-year old tea bushes cultivar DT1 of the 'TRI OR-CON' trial at St Coombs Estate, Talawakele. Three organic treatments were compared with conventional, inorganic management. Introduced organic treatments were tea waste, compost and Neem oil cake as soil amendments and managed according to International Federation of Organic Agriculture Movements guidelines. The treatments were arranged according to Randomized Complete Block design with four replicates and bushes were carefully uprooted and dry matter and nutrient partitioning were studied in different parts. The highest amount of nitrogen, phosphorus and potassium partitioning were found in the flush in all treatments compared to other parts of tea bushes. Organic treatments such as tea waste and Neem oil cake resulted the highest nitrogen content in flush as $4.06 \%$ and $4.05 \%$ respectively. Compost and conventional treatments showed lower nitrogen content of $3.59 \%$ and $3.56 \%$ respectively. However, the fallen leaves and branches also contained a certain amount of nutrients and that indicate the importance of fallen leaves as well as use of pruned residues for nutrient recycling. Dry matter partitioning was not significantly different in the above four treatments, whilst higher dry matter partitioning into stem part followed by root system and the lowest dry matter partitioning was observed in the leaf part of the bush. It is evident that partitioning of assimilates was similar in organically and conventionally managed tea bushes.
\end{abstract}

Key Words: Chemical fertilizer, Compost, Dry matter and nutrient partitioning, Neem Oil cake, Nutrient partitioning, Tea waste.

\section{INTRODUCTION}

Tea is the cheapest beverage in the world next to water. It is obtained from the tea plant (Camellia sinensis) (L) O. (Kuntze) which belongs to family Theaceae. Tea is a crop of wide adaptability to different climates and soils in various parts of the world. It is known to have originated in South-East China, and grown in countries with climates ranging from the Mediterranean type to hot, humid tropics (Carr and Stephens, 1992).

Ceylon tea from Sri Lanka identified as the best tea in the world has its inherent unique characteristics and reputation is held for more than a century. The influence of climatic conditions of its plantation imparts to produce a variety of flavors and aromas, synonymous with quality.

Due to the unfavorable health and environmental impacts in conventional farming, at present there is a widespread global interest for food crops grown under organic systems in cultivation. Organic farming is a system which avoids or largely excludes the use of synthetically compounded fertilizers, pesticides, growth regulators and livestock feed additives (Hajra, 2001). This system is also based on the dynamic interactions between the

\footnotetext{
${ }^{1}$ Department of Export Agriculture, Faculty of Agricultural Sciences, Sabaragamuwa University of Sri Lanka 32

${ }^{2}$ Tea Research Institute, Talawakele, Sri Lanka
} 
environment, soil, plants, animals and human beings. There is an increasing demand for organic tea, which is free of pesticide and other chemical residues (Ranasinghe et al., 2005). However, organic cultivation also has many criticisms, and the claim in decrease of productivity upon conversion to organic is an important one, amongst them. The productivity of the tea is reported to be decreased during conversion of existing conventional-inorganic systems to organic. Scientific validation and justification in use of organic tea therefore, will be extremely useful to convince and encourage tea growers (Mohotti and Mohotti, 2002).

Under commercial growing conditions its growth is modified by pruning to maintain the bushes pluckable and to stimulate vegetative growth. Since the tender growing shoots form the economic yield, the primary objective of the management of bushes is to maximize the generation of such shoots (Rahman, 1988). However, unlike in many other crops, economic yield of tea constitutes of a small fraction of the total dry matter produced by the bush, which is reported to vary from $7.5 \%$ to $9-12 \%$ (Hadfield, 1976).

Much of the work has been done in dry matter partitioning and harvest index of tea grown under the conventional farming system. There is no information on dry matter and nutrient partitioning and harvest index of organic tea. However, with the present criticisms on low productivity of organically grown plants, it is important to generate information on assimilate partitioning of organic tea. Further, it is also important to compare same with conventional tea, in order to examine changes due to different management options. The overall objective of the experiment was to identify the differences in dry matter and major nutrient partitioning in different parts of tea plants grown under organic and conventional systems.

\section{MATERIALS AND METHODS}

\section{Location}

The experiment was carried out at the Tea Research Institute of Sri Lanka, St. Coombs Estate, Talawakelle (latitude $6^{\circ}$ $80^{\prime} \mathrm{N}$, longitude $80^{\circ} 40^{\prime} \mathrm{E}$; and altitude 1382 m AMSL) during May to July 2008. Talawakelle is situated in WU3 (Up country Wet zone agro-ecological zone. Average annual rainfall of the area is about $2250 \mathrm{~mm}$ and annual average minimum, maximum temperatures were $14.2^{\circ} \mathrm{C}$ and $22.8^{\circ} \mathrm{C}$ respectively.

\section{Experimental site}

Two plant samples were collected from the on-going, long term 'TRI OR-CON' field trial, established in Field No. 13 of St. Coombs Estate. The tea (cultivar DT1) has been trench planted spacing of $4 \times 2$ feet in 1996, after two-year (1993 -1995) of rehabilitation period with Mana grass (Cymbopogon confertiflorus). Two sub plots containing 25 bushes per plot were separately monitored for growth and yield.

There were four treatments, which comprised three organic treatments compared with conventional treatment. The organic treatments, namely; 'tea waste (TW)', 'neem oil cake (NOC)' and 'compost (COM)' were managed according to the International Federation of Organic Agriculture Movements guidelines (IFOAM Standards).

Organic manures were incorporated with soil which classified under the great soil group of Red-yellow podzolic (Rhodudults/Tropudults;USDA classification) at the following rates:

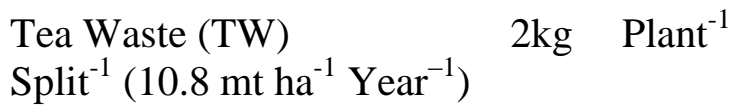


Neem Oil Cake (NOC)

$\operatorname{split}^{-1}\left(1.2 \mathrm{mt} \mathrm{ha}^{-1} \mathrm{Year}^{-1}\right)$

Compost (COM)

Split $^{-1}\left(10.8 \mathrm{mt} \mathrm{ha}^{-1}\right.$ Year $\left.^{-1}\right)$

TRI recommended inorganic fertilizers ( T200 recommendations as 2 splits as 200 $\mathrm{Kg} \mathrm{ha}{ }^{-1} \mathrm{Year}^{-1}$ ) and all the other recommended management practices were carried out in the conventional (CONV) treatment which was used as a control treatment. The fertilizer was applied in 3 splits per year with other management practices.

\section{Experimental design}

The above 4 treatments were arranged in the Randomized Complete Block Design (RCBD) with four replicates. Each block was separated with a deep drains and tall guard rows of tea bushes, which were maintained around plots to reduce the runoff of fertilizers and contamination of different treatments.

\section{Sampling}

Two plants were randomly selected from each plot and uprooted carefully, recovering all the roots by careful sieving process. Each plant was separated into different parts, i.e. leaves, stems, roots and flowers/ fruits. Leaves were further separated into immature (flush), mature and fallen leaves, while, stems and roots were also separated into collar, primary, secondary and tertiary branches, and mature and feeder roots, respectively.

Fresh weight of each sample was measured using digital electronic balance and recorded separately. Representative samples were then taken from each fraction consisting about $10 \%$ of total weight and oven dried at $85^{\circ} \mathrm{C}$ temperature until a constant weight was reached. The total dry weight for each bush was then extrapolated.

\section{Measurements}

\section{Nutrient analysis of plant parts and manures}

Fresh samples of plant and manure were oven dried at $70^{\circ} \mathrm{C}$ temperature for about 48 hours and then ground to pass a $0.6 \mathrm{~mm}$ sieve for nutrient analysis. Fine samples were directly used to analysis of Nitrogen, while, some samples were ashed for the analysis of Phosphorus and Potassium.

\section{Total nitrogen content}

Total nitrogen contents of the different parts of the plant and manures were measured using Kjeldahl method (Jessen and Johan, 1932). Samples of 0.2g were put in the digestion tubes and $0.5 \mathrm{~g}$ catalyst (containing anhydrous sodium sulphate, $\mathrm{CuSO}_{4}$ and selenium at a ratio of 125:5:1) was added. A $3 \mathrm{ml}$ of conc. $\mathrm{H}_{2} \mathrm{SO}_{4}$ was added in to the digestion tube and mixed. The samples were then digested in a block digester (Gerhadt Kjeldatherm, model KB 40, Gerhardt GmbH \& Co., KG, Bonn) at $420{ }^{0} \mathrm{C}$ in a fume cupboard for about 2 hours, until the solution was clear. One blank consisting of acid and catalyst was also digested.

When the samples were cold, it was distilled using a steam distillation unit (model: Vapodest 40, Gerhardt, Germany), adding $25 \mathrm{ml}$ distilled water and $25 \mathrm{ml}$ $40 \%$ w/v NaOH , and released $\mathrm{NH}_{3}$ was trapped in $2 \% \mathrm{w} / \mathrm{v}$ boric acid. This was then titrated to the end point with $0.1 \mathrm{~N}$ $\mathrm{HCl}$ using methyl red and bromocresol green dissolved in ethyl alcohol as the indicator, and total nitrogen content was determined as described by Bremner and Malvany (1982).

\section{Dry ashing of plant and manure samples}

Sample weight of $0.2 \mathrm{~g}$ was dry ashed at $470{ }^{\circ} \mathrm{C}$ in a muffle furnace (Heraeus, Type K1253, Australia). After complete combustion samples were added into $0.5 \mathrm{ml}$ of the digestion mixture (containing 
$25 \% \mathrm{HNO} 3$ and $25 \% \mathrm{HCl}$ ) and the ashed were fully dissolved. It was then heated for a few minutes to evaporate the acid and the residue was dissolved in $10 \mathrm{ml}$ of 0.05 $\mathrm{N} \mathrm{HCl}$. An aliquot was then used from the stock solution for the following analysis of $\mathrm{P}$ and $\mathrm{K}$.

\section{Phosphorus content}

Phosphorus content of the different parts of plant and manures were determined using $4 \mathrm{ml}$ aliquot from stock solution was pipetted in to a $25 \mathrm{ml}$ volumetric flask and $10 \mathrm{ml}$ Vando Molybdate color reagent (containing 25g Ammonium Molybdate, $1.25 \mathrm{~g}$ Ammonium Metavandate and $125 \mathrm{ml}$ conc. $\mathrm{HNO}_{3}$ ) was added to it. This was made to volume with distilled water, mixed and allowed to stand for 10 minutes. A blank was also carried out by using $10 \mathrm{ml}$ Vando Molybdate color reagent only in a $25 \mathrm{ml}$ volumetric flask and made to volume with distilled water. Absorbance was read at $425 \mathrm{~nm}$ against a blank in $1 \mathrm{~cm}$ cells using a spectrophotometer (GBC UV/VIS 911A, Australia). The total phosphorus content was calculated using equation suggested by Olsen et. al. (1954).

\section{Potassium content}

Potassium content of different parts of the plant and manures were determined by flame photometer (EEL Pep 7, Jenway, England).

\section{Data analysis}

Data were analyzed using GLM (General Linear Model) procedure in SAS (2003) statistical computer package and means of data were compared using Duncan Multiple Range Test (DMRT).

\section{RESULTS AND DISCUSSION}

\section{Nutrient composition of treatment sources}

Among the organic treatments, the highest nitrogen and potassium content was found in the tea waste (TW) followed by the neem oil cake (NOC). Compost (COM) had the highest phosphorus content compared to tea waste and neem oil cake (Table 1). Nutrient content of compost showed a variation owing to the use of different materials for compost making and as a consequent of lower nutrient content compared to other organic treatments was reported with compost. Chemical fertilizer (CONV) showed the highest nutrient content due to high amount of readily available nutrient fractions.

Table 1: The initial nutrient content $(\%)$ available in organic and inorganic treatments

\begin{tabular}{llll}
\hline Treatment & Nitrogen \% & Phosphorus \% & Potassium \% \\
\hline Tea Waste & 3.49 & 0.49 & 1.93 \\
Neem Oil Cake & 2.81 & 0.59 & 1.9 \\
Compost & $1.6-3.8$ & $1.5-3.7$ & $0.3-1.1$ \\
Chemical fertilizer & 46 & 32.5 & 60 \\
\hline
\end{tabular}




\section{Partitioning of dry matter}

There was no significant difference in the total dry weights of tea bushes among the four treatments (Table 2). However, tea grown in the conventional treatment had a substantially higher total dry weight than organic treatments, which was approximately $10 \%$ higher, followed by tea waste, neem oil cake and compost.

The dry matter partitioning in different parts of tea bushes under various management practices are presented in Table 3. The partitioning of dry matter into different parts of the bush was also not significantly $(\mathrm{p} \leq 0.05)$ affected by the treatments. However, results explained that the comparatively a lower dry matter partitioning into leaf parts was observed in all the treatments. Among the leaf part economically important flush (immature leaves) contained only about $1 \%$ of dry matter allocation followed by $7-8 \%$ in mature leaves.

Tea plant itself maintained in a vegetative phase continuously due to harvesting of immature leaves. Hence, the lowest dry matter allocation $(0.01 \%)$ was observed in flowers and fruits component comparatively to the other plant parts.
Among all the components, the highest dry matter partition was observed in the stem part and it is about 50-60\%. Furthermore, among different stem parts the tertiary branches contained the highest dry matter partition (24-28\%) followed by secondary branches (14-17\%), primary branches (11$13 \%)$ and collar region (8-10\%). Overall roots consisted of a substantial dry weight (23-32\%). Feeder roots are active for nutrients and water uptake. However, those contained the lowest dry matter allocation and the value was less than $1 \%$ out of total dry matter partition.

Overall results showed that dry matter partitioning into the leaves was quite low. Flush, which is the economically important part of the bush, and its dry matter partition was observed only about $1-2 \%$ of the total dry weight. The dry matter partitioning into the flowers and fruits was the lowest, followed by feeder roots. Out of the different parts of the tea bush, the highest dry matter partition was to the tertiary branches (24-28\%) and mature roots (23-32\%), in 12 year old tea bushes subjected to all treatments. Dry matter partition was the highest in the stem part, followed by root part in all treatment. Pruning of unnecessary stem parts and roots could induce high dry matter allocation into the economically important flush component.

Table 2: The total bush weight under different management systems

\begin{tabular}{ll}
\hline Treatment & $\begin{array}{l}\text { Total bush weight } \\
\text { g dry weight bush }\end{array}$ \\
\hline Tea Waste (TW) & $4044 \pm 12.38$ \\
Neem Oil Cake (NOC) & $3971 \pm 1.69$ \\
Compost (COM) & $3947 \pm 3.11$ \\
Conventional (CONV) & $4441 \pm 9.26$ \\
\hline
\end{tabular}

$\mathrm{P} \geq 0.05, \mathrm{n}=6, \pm$ Standard Deviation of mean, $\mathrm{CV} \%=7.81$ 
Table 3: The dry matter partitioning into different parts of the tea bushes as a percentage of the total dry weight, under different management practices

\begin{tabular}{lcccc}
\hline Part of Bush & TW \% & NOC \% & COM \% & CONV \% \\
\hline Flush & $1.17 \pm 1.02$ & $1.14 \pm 0.81$ & $1.16 \pm 0.68$ & $1.08 \pm 1.32$ \\
Mature leaves & $8.41 \pm 2.13$ & $8.45 \pm 1.58$ & $7.90 \pm 0.89$ & $7.46 \pm 1.02$ \\
Flowers \& Fruits & $0.01 \pm 0.00$ & $0.01 \pm 0.00$ & $0.02 \pm 0.00$ & $0.01 \pm 0.00$ \\
Tertiary branches & $26.42 \pm 5.36$ & $24.17 \pm 4.23$ & $27.90 \pm 8.01$ & $27.28 \pm 5.13$ \\
Secondary branches & $17.56 \pm 3.12$ & $14.25 \pm 2.68$ & $16.12 \pm 3.45$ & $17.14 \pm 4.56$ \\
Primary branches & $11.19 \pm 2.36$ & $11.76 \pm 4.50$ & $11.96 \pm 2.36$ & $13.88 \pm 4.3$ \\
Collar & $8.50 \pm 2.10$ & $8.03 \pm 2.35$ & $10.85 \pm 3.48$ & $6.48 \pm 4.56$ \\
Feeder roots & $0.31 \pm 0.12$ & $0.47 \pm 0.14$ & $0.37 \pm 0.25$ & $0.62 \pm 0.45$ \\
Mature roots & $26.42 \pm 5.47$ & $31.72 \pm 8.13$ & $23.74 \pm 6.00$ & $26.05 \pm 7.56$ \\
\hline
\end{tabular}

$\mathrm{P} \geq 0.05, \mathrm{n}=6, \pm$ Standard Deviation of mean

\section{Partitioning of nutrients Nitrogen}

Nitrogen partitioning into different parts of the tea bush under different treatments are presented in Table 4. Of the four treatments, tea waste and neem oil cake significantly increased nitrogen content in the flush, as $4.06 \%$ and $4.05 \%$ respectively, due to high content of nitrogen in treatment sources compared to conventional (3.56) treatment. Among the different organic treatments, compost showed the lowest nitrogen content $3.59 \%$ in flush. Whereas, the partitioning of nitrogen not all other parts of the plant including mature leaves, stem, flowers and roots was not significantly affected by the treatments.
The highest percentage of $\mathrm{N}$ was observed in the leaves of the bush, which were $(9 \%)$. The fallen leaves also contained substantial amounts of nitrogen (more than $2 \%$ ). Flowers and fruits also contained a considerable amount of nitrogen (more than $3 \%$ ). Of the other parts of the tea bush, the feeder roots and tertiary branches contained comparatively a higher nitrogen contents (1-2\%) irrespectively to the treatments. 
Table 4: Mean total Nitrogen content $(\%)$ of the different plant parts of four treatments

\begin{tabular}{lcccc}
\hline Part of Bush & TW \% & NOC \% & COM \% & CONV \% \\
\hline Flush & $4.06 \pm 0.34 \mathrm{a}$ & $4.05 \pm 0.24 \mathrm{a}$ & $3.59 \pm 0.38 \mathrm{~b}$ & $3.56 \pm 0.21 \mathrm{~b}$ \\
Mature leaves & $3.2 \pm 0.37$ & $3.3 \pm 0.26$ & $3.17 \pm 0.26$ & $3.17 \pm 0.17$ \\
Fallen leaves & $2.7 \pm 0.15$ & $2.41 \pm 0.38$ & $2.73 \pm 0.80$ & $2.28 \pm 0.28$ \\
Flowers and fruits & $3.25 \pm 0.40$ & $3.09 \pm 0.21$ & $3.15 \pm 0.15$ & $2.88 \pm 0.46$ \\
Tertiary branches & $1.29 \pm 0.29$ & $1.28 \pm 0.18$ & $1.2 \pm 0.26$ & $1.41 \pm 0.21$ \\
Secondary branches & $0.68 \pm 0.11$ & $0.59 \pm 0.06$ & $0.61 \pm 0.07$ & $0.62 \pm 0.05$ \\
Primary branches & $0.57 \pm 0.13$ & $0.56 \pm 0.07$ & $0.61 \pm 0.08$ & $0.55 \pm 0.08$ \\
Collar & $0.92 \pm 0.90$ & $1.08 \pm 1.25$ & $1.34 \pm 1.28$ & $2.39 \pm 1.30$ \\
Feeder roots & $1.62 \pm 0.11$ & $1.57 \pm 0.08$ & $1.65 \pm 0.08$ & $1.53 \pm 0.19$ \\
Mature roots & $0.69 \pm 0.17$ & $0.64 \pm 0.17$ & $0.74 \pm 0.21$ & $0.82 \pm 0.07$ \\
\hline P
\end{tabular}

$\mathrm{P} \leq 0.05, \mathrm{n}=6, \pm$ Standard deviation of mean,

Means with same letters are not significantly different

\section{Phosphorus}

The contents of phosphorus was not significantly $(\mathrm{p} \geq 0.05)$ different among the treatments in any part of the tea bush (Table 5). The highest percentage of $\mathrm{P}$ was observed in the fallen leaves $(0.17-0.21 \%)$, and flowers and fruits (0.15-0.23). Stem and roots showed the lowest amount of phosphorus which was less than $0.1 \%$.

\section{Potassium}

The contents of potassium was also not significantly $(p \geq 0.05)$ different among the treatments in any of the parts of the tea bush (Table 6). The highest percentage of potassium was observed in tea flush, which was around $1 \%$. The mature leaves and fallen leaves also contained relatively a higher amount of potassium content compared to other parts. Flowers and fruits also contained a more than $0.5 \%$ potassium. Roots also contained a higher amount of potassium which was about 0.5$0.7 \%$. Of the other parts of the tea bush, stem parts contained the least amount of potassium about less than $0.3 \%$.
Overall results were revealed that the highest percentage of $\mathrm{N}$ and $\mathrm{K}$ were observed in the immature leaves tea flush, followed by mature leaves. Fallen leaves and flowers and fruits also contained a considerable amount of nutrients, showing their importance in nutrient recycling. Of the other parts of the tea bush, the feeder roots contained higher nutrient contents.

Among the stem parts tertiary branches contained the highest amount of nutrients collectively the stem parts contained a larger amount of nutrients $\mathrm{N}, \mathrm{P}$ and $\mathrm{K}$ as they represent the highest dry matter content of the bush (Table 3 ).

Results on nitrogen partitioning indicates that, the highest nitrogen content was found in organic treatments and the lowest nitrogen content was found in conventional treatment. According to Table 1, the initial measurement tea waste was the highest nitrogen content followed by, neem oil cake and compost and these may have resulted in a higher nitrogen content with organic treatments compared to conventional fertilizers. 
Although, the highest nutrient content was found in conventional treatment (Table 1). Due to high leaching ability of inorganic fertilizer, soil was not capable of retaining those nutrients in longer period (Gupta, 2003). This was resulted in a lower nutrient content in tea bushes. Only about $40 \%$ of fertilizers can be utilized plants and the balance is lost due to leaching and evaporation.
The tea bush was maintained continuously in vegetative phase by management practices in commercial cultivation. The flush was being harvested once in every 48 days plucking rounds. These practices made the flush to be continuously and actively growing. Nitrogen is a constituent in proteins and amino acids which are important building blocks of growing parts of plant (Rao, 1998). Therefore, the flush contained a considerable amount of $\mathrm{N}$.

Table 5: Mean Phosphorus content (\%) of the different plant parts of four treatments

\begin{tabular}{lcccc}
\hline Part of Bush & TW \% & NOC \% & COM \% & CONV \% \\
\hline Flush & $0.17 \pm 0.04$ & $0.15 \pm 0.05$ & $0.13 \pm 0.02$ & $0.14 \pm 0.06$ \\
Mature leaves & $0.13 \pm 0.07$ & $0.11 \pm 0.03$ & $0.1 \pm 0.06$ & $0.08 \pm 0.06$ \\
Fallen leaves & $0.18 \pm 0.04$ & $0.17 \pm 0.03$ & $0.21 \pm 0.03$ & $0.17 \pm 0.04$ \\
Flowers and fruits & $0.18 \pm 0.04$ & $0.23 \pm 0.04$ & $0.21 \pm 0.04$ & $0.15 \pm 0.04$ \\
Tertiary branches & $0.1 \pm 0.02$ & $0.1 \pm 0.03$ & $0.09 \pm 0.01$ & $0.1 \pm 0.02$ \\
Secondary branches & $0.03 \pm 0.01$ & $0.03 \pm 0.01$ & $0.03 \pm 0.01$ & $0.03 \pm 0.01$ \\
Primary branches & $0.03 \pm 0.01$ & $0.03 \pm 0.01$ & $0.02 \pm 0.00$ & $0.02 \pm 0.01$ \\
Collar & $0.03 \pm 0.00$ & $0.04 \pm 0.00$ & $0.04 \pm 0.00$ & $0.04 \pm 0.00$ \\
Feeder roots & $0.09 \pm 0.02$ & $0.09 \pm 0.02$ & $0.08 \pm 0.02$ & $0.10 \pm 0.02$ \\
Mature roots & $0.08 \pm 0.20$ & $0.08 \pm 0.04$ & $0.04 \pm 0.04$ & $0.04 \pm 0.01$ \\
\hline P
\end{tabular}

$\mathrm{P} \geq 0.05, \mathrm{n}=6, \pm$ Standard deviation of mean

Of the treatments, tea waste (TW) and neem oil cake (NOC) had the highest amount of nitrogen content in the flush. Tea waste is known to contain a higher percentage of nitrogen than most of other organic manures (Krishnapillai, 1981). Oil cakes also contained high levels of nutrients (Dahama, 1997). Available nutrient content of different parts of tea bushes is corresponding with the nutrient contents of manures (Table 1). Although, the TRI recommendations were based on the nutrient requirements of tea plants, it is based on the artificial fertilizer, which releases the nutrients quickly once applied. On the other hand, the organic manures could release their nutrients gradually into the soil for a much longer duration (Dahama, 2003). Presence of organic matter in soil also helped to regulated the
$\mathrm{pH}$ level through buffering effect. Such good $\mathrm{pH}$ level and more nutrients in soil help to increase CEC. The nutrient content of compost depends on the consistency of the ingredients that had been used in its preparation (Sharma, 2002) and the level of its degradation. Therefore, the nutrient content of compost is highly variable from sample to sample. Hence, differences could be seen in terms of the treatments.

The mature leaves also contained a considerable amount of nutrients and these were less than in flush, but more than in all the other parts of the bush. The fallen leaves had quite high levels of nutrient, but were much less than in fresh, mature leaves, indicating mobility of the elements prior to their senescence. 
The growing parts, i.e. tertiary branches and feeder roots had higher nutrients contents than their more mature counterparts, i.e. secondary and primary branches and mature roots indicating their requirement in growth.

With overall data of nutrient partitioning in different parts of tea bushes; it was not observed significant differences in phosphorus and potassium partitioning between the treatments. While, among the different treatments, somewhat higher nitrogen and phosphorus content were found in tea waste (TW) treatment compared to the neem oil cake (NOC), compost (COM) and conventional (CONV) in most of the parts, i.e. Mature and immature leaves, feeder roots, fallen leaves, flowers and fruits.

Overall data reviewed that, it was not observed highly significant differences in dry matter or nutrient partitioning between different parts of the bush among the treatments. It indicated that the feasibility of growing tea organically, without affecting plant growth. In some early studies done on the same experiment, similar responses have been recorded on the yield and yield components (Mohotti et al., 2002).

However, the observations obtained from the study were against the general understanding of literature. According to the results of study that, the yield drops could not occur once the tea cultivation is being converted to organic. The ongoing 'TRI OR-CON' trial had been established in 1996 and the different treatments were imposed from the time of planting. The practices were carried out with a scientific basis and due attention was given for carrying out all the practices as per the International Federation of Organic Agriculture Movements (IFOAM) and tea Research Institute (TRI) guidelines. Therefore, it can be postulated that if organic tea cultivation is being carried out as per the guidelines, it is technically equally feasible as conventional tea cultivation.

\section{CONCLUSIONS}

The study was undertaken to evaluate and compare the nutrient and dry matter partition differences of organically and conventionally grown tea plants. It is evident that partitioning of dry matter was similar in organically and conventionally managed tea bushes. The partitioning of the nutrients also did not highly significantly vary between organically and conventionally grown tea. Among all the plant parts, there is high nutrient partitioning into the flush or the harvestable portion which is very important in final product in tea. The fallen leaves also contained fairly high amount of nutrients. It shows the importance of fallen leaves in nutrient recycling. Moreover, as the organically grown tea produces the same yield as conventionally grown tea, organic tea cultivation can become a viable industry. The study shows the technical feasibility of organic tea cultivation in the up country of Sri Lanka, but an economic analysis should be carried out to find out the economic feasibility.

\section{ACKNOWLEDGMENTS}

It is my pleasure to acknowledge to $\mathrm{Mr}$. J. B. D. A. P. Kumara, Lecturer, Department of Export Agriculture, Faculty of Agricultural Sciences, Sabaragamuwa University of Sri Lanka, Belihuloya, for providing me this opportunity. I thank also Dr. Sarath I Abeysinghe, Director, Tea Research Institute, Talawakelle, for granting me permission. It is my duty to thank Mrs. Vasanthi Sidhakaran and Mrs. Shanthi Navarathne, Experimental Officers, and all the other members of staff of the Plant Physiology Division, Tea Research Institute, Talawakelle, for the constant help given to me during my project period. 


\section{REFERENCES}

Bremner, J. C and C. S. Malvany (1982), Total Nitrogen, In: Methods of soil analysis, part 2, second edition, American Society of Agronomy, pp: 595-622

Carr, M. K. V, and W. Stephens (1992), Climate, weather and the yield of tea, In: Tea Cultivation to consumption, Wilson K, C. and Cliftord M.N. (eds) Champman and Hall, London, pp. 87-135

Dahama, A. K. (1997), Organic manure, In: Organic Farming, ed. A.K. Dahama, Rajasthan Agriculture University, Bikaner, pp: 123-246

Dahama, A. K. (2003), Use of traditional additives for organic farming, In: Organic farming for sustainable agriculture, $2^{\text {nd }} \mathrm{Ed}$, ed. A.K. Dahama, Agrobios, India, pp. 91-139

Gupta, P. K. (2003), Fertilizer, In: A hand book of soil, fertilizer and manure, $2^{\text {nd }} \mathrm{Ed}$, (ed.) P. K. Gupta, Agrobios, India, pp: 210-269

Hadfield, W. (1976), The effect of high temperature on some aspects of the physiology and cultivation of the tea bush in North East India. In: Proc. $16^{\text {th }}$ Symposium, British Ecological Society, Blackwells

Hajra, N. G. (2001), Organic tea farming, In: Tea Cultivation Comprehensive Treatise, 14; pp: 475-489

Jessen-Hansen, H. (1932) Johan Kjeldahl, In: Meisen, V. Prominent Danish Scientists through the Ages. University Library of Copenhagen 450th Anniversary. Levin \& Munksgaard, Copenhagen, pp: 169-172

Krishnapillai, S. (1981), effect of waste tea (tea fluff) on growth of young tea plants, Tea Quarterly, 50 (3) ,pp: 98-104

Mohotti, K. M. and A. J. Mohotti (2002), The feasibility of organic tea production: A Preliminary examination, Proceedings of the $204^{\text {th }}$ Experimental and Extension Forum, Tea Research Institute of Sri Lanka, pp: 23-28

Mohotti, A. J. Mohotti, K. M., Premaratne, M. P. T. and U. R. Sangakkara (2002), comparison of yield and its components of tea supplemented with various manures under organic and conventional cultivation. In: Organic production, Ecology and Biodiversity. The fifth IFOAM-Asia scientific conference, pp: 90-92

Olsen, S.R., C.V. Cole, F.S. Watanabe, and L.A. Dean. (1954), Estimation of available phosphorus in soils by extraction with sodium bicarbonate. U.S. Dep. of Agric. Circ. pp: 939

Ranasinghe, W. S. C., Abeysinghe, I. S. B., Jayasundara, M. J., Liyanage, A. C. and T. U. S. Peiris (2005), Comparison of quality parameters of organic vs conventionally grown tea. Sri Lanka Journal of Tea Science, pp: 92

Rahman, F. (1988), Physiology of the tea bush, Two and a Bud, 35, pp:1-14

Rao, R. A. V. S. S. (1998), Protiens, In: A text book of Biochemistry, $8^{\text {th }}$ Ed, R. A. V. S. S. Rao and A. Suryalakshmi (eds), UBS publications ltd, India, pp: 70-98

Sharma, A. K. (2002), Production of compost. In: A hand book of organic farming, ed. A. K. Sharma, Agrobios, India, pp: 148-215

Sivapalan, P., S. Kulasegaram and A. Kathiravetpillai (eds), (1986), Hand Book on tea, Tea Research Institute of Sri Lanka, pp: 1-19 